\title{
Survival Prognosis in Very Old Adults
}

\author{
Mikael Thinggaard, MSc, ${ }^{* \dagger}$ Matt McGue, PhD, ${ }^{*}$ Bernard Jeune, MD, ${ }^{*}$ Merete Osler, MD, PhD, $* \xi$

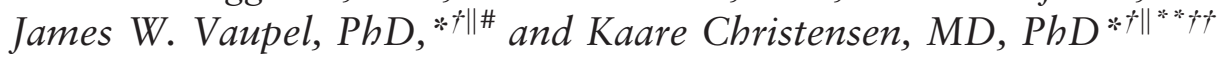

OBJECTIVES: To determine whether simple functional indicators are predictors of survival prognosis in very old adults.

DESIGN: In-person survey conducted over a 3-month period in 1998; assessment of survival over a 15-year followup period.

SETTING: Denmark.

PARTICIPANTS: All 3,600 Danes born in 1905 and living in Denmark in 1998, were invited to participate regardless of residence and health; 2,262 (63\%) participated in the survey: $1,814(80.2 \%)$ in person and 448 $(19.8 \%)$ through a proxy.

MEASUREMENTS: Socioeconomic factors, medications and diseases, activities of daily living, physical performance, cognition, depression symptomatology, self-rated health, and all-cause mortality, evaluated as average remaining lifespan and chance of surviving to 100 years.

RESULTS: Men aged 92 to 93 had an overall $6.0 \%$ chance of surviving to 100 years, whereas the chance for women was $11.4 \%$. Being able to rise without use of hands increased the chance for men to $11.2 \%$ (95\% confidence interval $(\mathrm{CI})=7.7-14.7)$ and for women to $22.0 \%$ $(95 \% \mathrm{CI}=18.9-25.1)$. When combining this with a MiniMental State Examination (MMSE) scores from 28 to 30, the chances were $21.7 \%(95 \% \mathrm{CI}=11.5-31.9)$ for men and $34.2 \%(95 \% \mathrm{CI}=24.8-43.5)$ for women.

CONCLUSION: Chair stand score combined with MMSE score is a quick and easy way to estimate overall chance of survival in very old adults, which is particularly relevant

From the *Danish Aging Research Center; ${ }^{\dagger}$ Epidemiology, Biostatistics and Biodemography, University of Southern Denmark, Odense, Denmark; ${ }^{\star}$ Department of Psychology, University of Minnesota, Minneapolis, Minnesota; ${ }^{\S}$ Research Centre for Prevention and Health, Glostrup University Hospital, Glostrup; "Max-Planck Odense Center on the Biodemography of Aging, University of Southern Denmark, Odense, Denmark; "Max Planck Institute for Demographic Research, Rostock, Germany; **Departments of Clinical Genetics; and ${ }^{\dagger \dagger}$ Clinical Biochemistry and Pharmacology, Odense University Hospital, Odense, Denmark.

Address correspondence to Mikael Thinggaard, Danish Aging Research Center, University of Southern Denmark, J.B. Winsloews Vej 9B, DK5000 Odense C, Denmark. E-mail: MThinggaard@health.sdu.dk

DOI: $10.1111 /$ jgs. 13838 when treatment with potential side effects for nonacute diseases is considered. J Am Geriatr Soc 64:81-88, 2016.

Key words: mortality; nonagenarians; clinical decision; chair stand; Mini-Mental State Examination

$T$ he chance of surviving to the age of 90 has increased markedly over the last 50 years in high-income countries, and will probably continue to rise with successive cohorts. ${ }^{1,2}$ In the United States, the number of nonagenarians has increased from approximately 230,000 in 1960 to approximately 1.8 million in 2010, and in the five biggest countries in the European Union (Germany, France, the United Kingdom, Italy, Spain) the number has increased from approximately 250,000 to 1.6 million, which is almost 7 times as many nonagenarians, compared with 1.5 times as many people in the total population of these countries in 1960 as in 2010.

With this growing number of oldest old adults, ageism has been decreasing in recent decades, and it has now become generally unacceptable to deny medical procedures to people aged 80 and older using advanced age as the sole argument. ${ }^{3}$ Research has also emerged that investigates medical procedures for very old adults, ${ }^{4-6}$ but life expectancy for very old adults is still short in most high-income countries, ranging from around 8 to 10 years for 80 -yearolds to 4 to 5 years for 90 -year-olds (online Table S1). ${ }^{7}$ Hence, overtreatment of very old adults is still a general concern, and potential side effects of treatment have to be balanced with the overall survival prognosis, which is generally based on the overall chance of survival to a given age or overall life expectancy. ${ }^{8}$ It has been argued that clinicians should offer to discuss the overall survival prognosis with patients aged 85 and older. ${ }^{8}$ There is large variation in health and life expectancy in very old adults, which also should be taken into consideration before treatment is provided. Comprehensive geriatric assessments exist, but they are generally time-consuming and mostly validated in people aged 70 to $80 .^{9-11}$ Simple, easy-to-use tools that can help predict the chance of individual survival in very old adults would be useful in 
clinical decision-making for general practitioners, but only a few studies have investigated factors that predict mortality in very old adults. In a study of 186 Spanish nonagenarians, comorbidity and cognition assessed over a 5-year follow-up period were found to be the best predictors of mortality. ${ }^{12}$ In a study of 888 Finnish people aged 90 and older, activities of daily living (ADLs), self-rated health, and being institutionalized over a 9-year period were found to be associated with mortality. ${ }^{13}$ A study of 19,340 Americans, 335 of whom were nonagenarians, showed that functional limitation in nonagenarians was a better predictor of mortality than chronic conditions. ${ }^{14}$ In a study of 335 Italian people aged 80 and older, walking speed and five-time chair stand test were found to be associated with mortality. ${ }^{15}$ Walking speed and chair stands has also been shown to predict subsequent disability and mortality in people aged 70 and older. ${ }^{16,17}$ Unfortunately, most of these studies presented hazard ratios, which can be difficult to use in clinical decision-making and to communicate to people.

This study comprised a Danish birth cohort followed from age 92 or 93 until the cohort was almost extinct. The aim was to identify measures that predict remaining lifespan and chance of surviving to 100 years and that can be easily administered in a primary care setting without specialized equipment.

\section{METHODS}

\section{Study Population and Measures}

The study population comprised all people born in 1905 who were alive in 1998 and living in Denmark at the time of the survey, which took place from August to October. They were all invited to participate, regardless of residence, health, or cognitive status, giving a total of 3,600 people, 2,262 $(62.8 \%)$ of whom participated: 1,814 $(80.2 \%)$ in person and $448(19.8 \%)$ through a proxy. Interviewers from a survey agency interviewed participants in their homes. The study instrument consisted of an interview, physical and cognitive tests, and a deoxyribonucleic acid sample. The ethical committee system in Denmark approved the study (Trial VF20040240), and all participants provided informed consent to participate. The study has been described in detail previously and is a follow-up of a study that showed that disability and cognitive impairment predicted mortality over 15 months. ${ }^{18-20}$ The selected variables in this study were measures of socioeconomic factors, medications and diseases, ADLs, physical performance (chair stand, grip strength, walking speed), cognition (Mini-Mental State Examination (MMSE), composite of five cognitive tests sensitive to age-related changes), depression symptomatology, and self-rated health. The measures were chosen based on the criterion that they have generally been used to predict mortality in individuals aged 70 and older. Online Appendix S1 describes these measures in detail.

\section{Survival}

All members of the Danish 1905 cohort were followed from the baseline interview period through January 1,
2013, in the Danish Civil Registration system, which registers date of death or emigration of all Danish citizens. ${ }^{21}$ Only two persons emigrated in the follow-up period and were lost to follow-up at the emigration date.

\section{Statistical Analysis}

Multivariable logistic regression analyses were performed to assess the association between the many potential measures for a 92- or 93-year-old person and the chance of surviving to 100 years. C-statistics (area under the receiver operating curve) were estimated from the multivariable logistic regressions to assess the ability of these measures to predict the chance of surviving to 100 . $\mathrm{C}$-statistics range from 0.5 and 1 and are a rough guide for classifying the prediction of the outcome $(0.5-0.6=$ failed prediction, $0.6-0.7=$ poor prediction, $0.7-0.8=$ fair prediction, $0.8-0.9=$ good prediction, $0.9-1=$ excellent prediction). Because there was an exact age at death for all members of the cohort except for six persons $(0.1 \%)$, the average remaining lifespan was simply calculated as mean time to death, emigration, or time to January 1, 2013. Because only two persons $(0.06 \%)$ emigrated, and four $(0.1 \%)$ were still alive after January 1,2013 , the above measures would essentially be unbiased. All analyses were performed separately for each sex, and because the age range was 92 to 93 , and $80 \%$ were aged 92.8 to 93.6, adjusting for age was not necessary.

Multiple imputation using a full conditional specification model (chained equation) in the analysis was used to account for missing data, which was mainly due to the interview being conducted through a proxy or the 1905 cohort member being physically or mentally unable to perform the tests. ${ }^{22}$ Online Appendix S1 describes the multiple imputation in detail. Statistical analysis was performed using Stata version 13.1 (Stata Corp, College Station, TX).

\section{RESULTS}

The prevalence of indicators of poor health was generally high and higher in women than men, except for myocardial infarction (Table 1). Over the 15-year follow-up from 1998 , four $(0.1 \%)$ of the 3,600 persons were still alive, and only two $(0.06 \%)$ were lost to follow-up due to emigration. Men had a significantly lower average remaining lifespan than women $(2.7$ vs 3.3 years, $P<.001)$, and men had a $6.0 \%$ chance of surviving to 100 years, whereas the chance for women was almost twice as high (11.4\%). Nonparticipation, in-person interview, and proxy interview were significantly associated with mortality. Male nonparticipants had a $4.2 \%$ chance $(95 \%$ confidence interval $(\mathrm{CI})=2.1-7.3)$ of surviving to 100 years, those interviewed in person had an $8.1 \%$ chance $(95 \% \mathrm{CI}=5.8$ 10.9), and those interviewed through a proxy had a $0 \%$ chance $(95 \% \mathrm{CI}=0.0-4.0)$. For women, the chances of surviving to 100 years were $9.4 \%(95 \% \mathrm{CI}=7.7-11.3)$ for nonparticipants, $15.6 \%(95 \% \mathrm{CI}=13.7-17.7)$ for inperson interviewees, and $1.7 \%(95 \% \mathrm{CI}=0.6-3.6)$ for proxy interviewees.

All ADL, physical condition, cognitive, depression symptomatology, and self-rated health measures were significantly associated with average remaining lifespan and 
Table 1. Description of the Sample and Estimated Prevalence of Selected Measures at Age 92 to 93 for the Danish 1905 Birth Cohort $(\mathrm{N}=2,262)$

\begin{tabular}{|c|c|c|c|c|c|c|}
\hline \multirow[b]{2}{*}{ Factor } & \multicolumn{3}{|c|}{ Men, $\mathrm{n}=584$} & \multicolumn{3}{|c|}{ Women, $n=1,678$} \\
\hline & n (\%) & $\begin{array}{c}\text { Missing, } \\
\text { n (\%) }\end{array}$ & $\begin{array}{l}\text { Estimated } \\
\text { Prevalence, } \\
\%(95 \% \mathrm{Cl})\end{array}$ & n (\%) & $\begin{array}{c}\text { Missing, } \\
\text { n (\%) }\end{array}$ & $\begin{array}{l}\text { Estimated } \\
\text { Prevalence, } \\
\%(95 \% \mathrm{Cl})\end{array}$ \\
\hline \multicolumn{7}{|l|}{ Socioeconomic factors } \\
\hline Elementary school education & $271(48.6)$ & $26(4)$ & $48.3(44.1-52.5)$ & $1,204(74.1)$ & $54(3)$ & $74.0(71.8-76.1)$ \\
\hline Social class IV-V ${ }^{a}$ & $238(41.8)$ & $14(2)$ & $41.7(37.7-45.8)$ & $1,359(83.0)$ & $40(2)$ & $82.9(81.1-84.8)$ \\
\hline Body mass index $<22 \mathrm{~kg} / \mathrm{m}^{2}$ & $154(26.8)$ & $10(2)$ & $27.0(23.4-30.7)$ & $734(45.4)$ & $62(4)$ & $45.5(43.1-47.9)$ \\
\hline Smoking (now) & $142(24.8)$ & $12(2)$ & $24.9(21.3-28.4)$ & $170(10.3)$ & $30(2)$ & $10.3(8.9-11.8)$ \\
\hline \multicolumn{7}{|l|}{ Disease (present or prior) } \\
\hline Cancer & $31(5.3)$ & $2(0.3)$ & $5.3(3.5-7.1)$ & $135(8.1)$ & $13(1)$ & $8.1(6.8-9.4)$ \\
\hline Chronic bronchitis & $53(9.1)$ & $2(0.3)$ & $9.2(6.8-11.5)$ & $172(10.3)$ & $11(1)$ & $10.4(8.9-11.8)$ \\
\hline Myocardial infarction & $47(8.1)$ & $1(0.2)$ & $8.1(5.8-10.3)$ & $96(5.8)$ & $15(1)$ & $5.8(4.6-6.9)$ \\
\hline Stroke & $71(12.2)$ & $2(0.3)$ & $12.3(9.6-15.0)$ & $189(11.3)$ & $19(2)$ & $11.5(9.9-13.0)$ \\
\hline \multicolumn{7}{|c|}{ (1) } \\
\hline ADL score $<1.3$ & $141(26.4)$ & $49(8)$ & $26.3(22.7-30.0)$ & $636(40.9)$ & $123(7)$ & $40.0(37.6-42.4)$ \\
\hline Katz severely disabled & $108(18.7)$ & $6(1)$ & $18.9(15.7-22.1)$ & $352(21.3)$ & $27(2)$ & $21.5(19.5-23.4)$ \\
\hline Katz moderately disabled & $180(31.1)$ & $6(1)$ & $31.1(27.3-34.9)$ & $625(37.9)$ & 27 (2) & $37.9(35.6-40.2)$ \\
\hline \multicolumn{7}{|l|}{ Physical condition } \\
\hline Not able to stand from a chair & $33(6.9)$ & $109(19)$ & $11.5(8.4-14.6)$ & $99(7.9)$ & $428(26)$ & $15.9(13.7-18.1)$ \\
\hline Able to stand from a chair with use of hands & $154(32.4)$ & 109 (19) & $35.0(30.7-39.3)$ & $529(42.3)$ & $428(26)$ & $42.8(40.0-45.6)$ \\
\hline Grip strength $1-18 \mathrm{~kg}$ in men, $1-10 \mathrm{~kg}$ in women & $118(25.6)$ & $123(21)$ & $29.6(25.3-33.9)$ & $312(26.7)$ & $508(30)$ & $30.1(27.4-32.7)$ \\
\hline Not able to walk & $55(12.9)$ & $121(21)$ & $19.3(15.7-22.9)$ & $144(13.0)$ & $459(27)$ & $21.2(18.8-23.5)$ \\
\hline \multicolumn{7}{|l|}{ Cognition } \\
\hline MMSE score $0-17$ & $61(14.3)$ & $158(27)$ & $19.0(15.3-22.6)$ & $234(20.7)$ & $546(33)$ & $26.8(24.1-29.4)$ \\
\hline MMSE score 18-23 & $127(30)$ & $158(27)$ & $33.4(29.1-37.7)$ & $365(32)$ & $546(33)$ & $35.4(32.5-38.4)$ \\
\hline Fluency 0-7 words & 76 (16.4) & $76(13)$ & $24.1(19.0-29.1)$ & $283(22.9)$ & $283(17)$ & $32.9(29.4-36.4)$ \\
\hline Cognitive composite score $\leq-0.5$ stand & $91(21.5)$ & $160(27)$ & $33.4(28.5-38.3)$ & $237(21.4)$ & $568(34)$ & $34.1(30.8-37.5)$ \\
\hline \multicolumn{7}{|l|}{ Depression symptomatology and self-rated health } \\
\hline Depression symptomatology (29-52) & $103(25.1)$ & $174(30)$ & $32.5(28.3-36.6)$ & $316(28.4)$ & $565(34)$ & $37.3(34.4-40.1)$ \\
\hline Self-rated health very poor to poor & $51(10.3)$ & $160(27)$ & $12.5(9.3-15.8)$ & $153(11.6)$ & $568(34)$ & $14.3(12.1-16.4)$ \\
\hline Apolipoprotein E $\varepsilon 4$ carrier & $99(21.7)$ & $127(22)$ & $21.6(17.8-25.4)$ & 255 (21.9) & $514(31)$ & $21.8(19.4-24.2)$ \\
\hline
\end{tabular}

Prevalence was estimated using multiple imputation analysis to take into account missing values.

${ }^{a}$ Housewives, nonskilled workers, smallholders and employees without subordinates, with no further education and a job demanding no expertise.

$\mathrm{CI}=$ confidence interval; $\mathrm{ADL}=$ activity of daily living; MMSE = Mini-Mental State Examination.

chance of surviving to 100 years when analyzed separately for men and women (Figures 1 and 2). Within each category of ADLs and physical and cognitive ability, the measures had almost the same association with chance of surviving to 100 years and average remaining lifespan. Belonging to the category with the best ADL, physical condition, cognitive, depression symptomatology, or self-rated health measurement resulted in an absolute gain of 0.8 to 1.7 years. Being able to rise from a chair without using hands increased the chance of surviving to 100 years to $11.2 \%(95 \% \mathrm{CI}=7.7-14.7)$ for men and $22.0 \%(95 \%$ $\mathrm{CI}=18.9-25.1)$ for women from $1.5 \%$ for men and $2.4 \%$ for women who could not do so. With regard to cognition, the chance of surviving to 100 for men with an MMSE score of 24 or greater was $11.2 \%(95 \% \mathrm{CI}=7.9-15.5)$, and the chance for women was $19.3 \%(95 \% \mathrm{CI}=16.3-$ 22.6); whereas it was $2.9 \%$ for men and $8.6 \%$ for women with an MMSE score of less than 24. Body mass index (BMI), number of medications, stroke, and apolipoprotein E were also associated with survival, although the associations for these measures were not as strong as for the ADL, physical condition, cognitive, depression symptomatology, and self-rated health measures. Socioeconomic condition, smoking, cancer, chronic bronchitis, and myocardial infarction were not associated with mortality.

The full multivariable logistic regressions showed that the chance of surviving to 100 was most strongly associated with ADL, physical condition, and cognitive measures (Table 2). The c-statistic was estimated to be $0.86(95 \%$ $\mathrm{CI}=0.81-0.92)$ for men and $0.79(95 \% \mathrm{CI}=0.76-0.82)$ for women. In the logistic regressions with only one ADL and physical condition measure and one cognitive measure, the c-statistics ranged from 0.74 to 0.81 for men and from 0.70 to 0.75 for women. For the chair stand and the MMSE, the c-statistic was $0.77(95 \% \mathrm{CI}=0.71-0.84)$ for men and $0.73(95 \% \mathrm{CI}=0.70-0.77)$ for women. Given different groupings of chair stand and MMSE score, the prevalence of persons in the group, the chance of surviving to 100 , and average remaining lifespan is shown in Table 3. The chance of surviving to 100 when an individuals was able to rise from a chair without using the hands and had an MMSE score of 24 or greater was $14.0 \%(95 \%$ $\mathrm{CI}=9.8-19.7)$ for men and $27.3 \%(95 \% \mathrm{CI}=23.0-32.2)$ for women. The average remaining lifespan for this group 

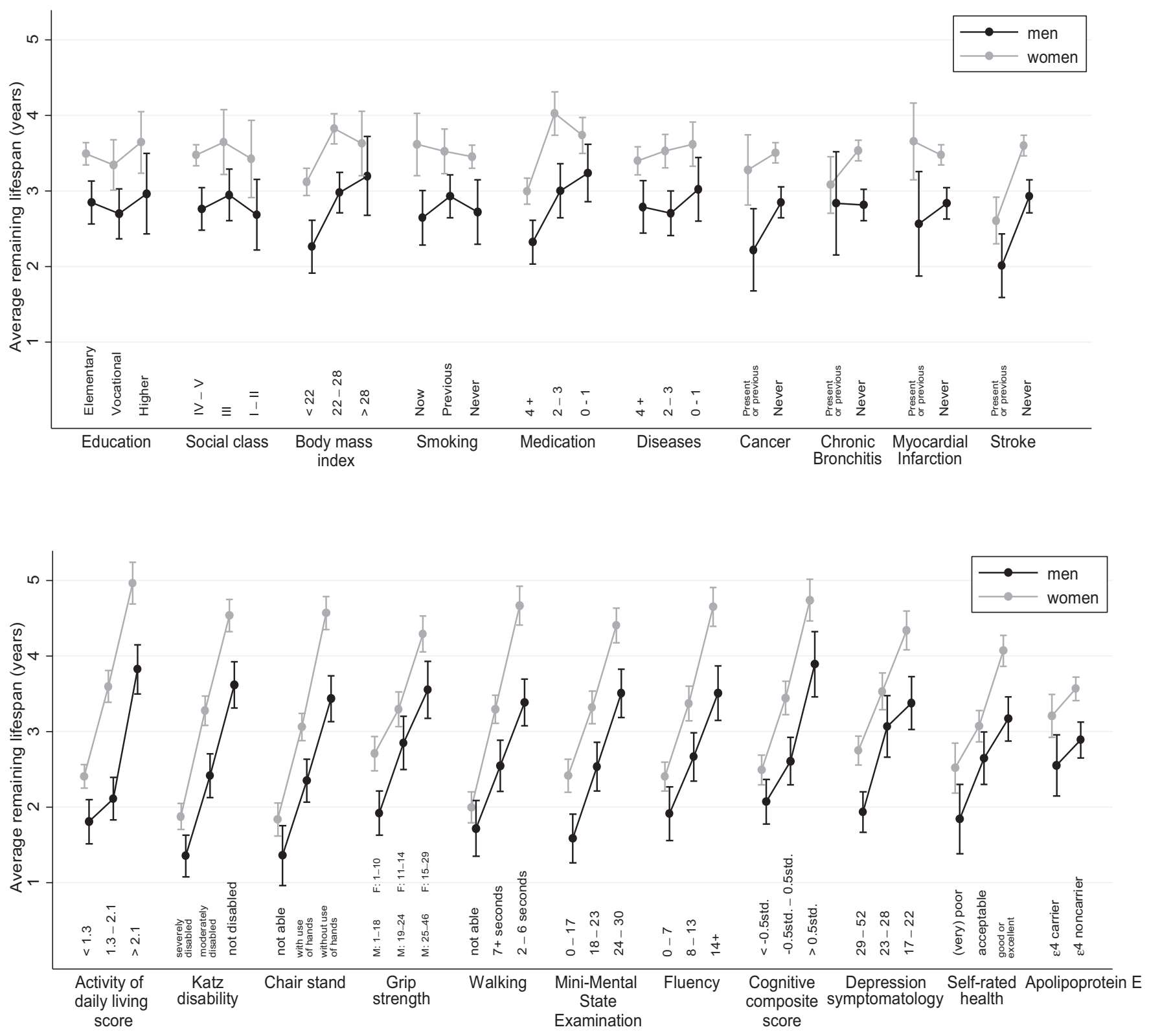

Figure 1. Average remaining lifespan estimated using multiple imputation. The categories are the same for all measures for both sexes except for grip strength, as indicated in the figure. Bars indicate $95 \%$ confidence intervals.

was 3.7 years $(95 \% \mathrm{CI}=3.3-4.1)$ for men and 5.1 years $(95 \%$ CI $=4.8-5.4)$ for women. This group constituted $33 \%$ of all men and $22 \%$ of all women. The likelihood of reaching 100 increased to $21.7 \%$ and average remaining lifespan increased to 4.3 years for men who were able to rise from a chair without using the hands and had an MMSE score of 28 or greater and to $34.2 \%$ and 5.6 years, respectively, for women. Replacing the chair stand with Katz disability in this combination showed similar results (Table 3).

Multiple imputation was used in all analyses. Analysis of the data using only complete case analysis would have generated bias for the measures with many missing data mainly due to interviews being conducted through a proxy, which was $19.8 \%$ of all interviews (Table 1, Online Table S2), but there were very few missing data for the majority of the measures (e.g., for Katz disability, socioeconomic position, BMI), and for these measures, the results were virtually identical between complete case analysis and multiple imputation.

\section{DISCUSSION}

Basic physical and cognitive measures are highly informative in predicting chance of survival in very old adults. At the age of 92 or 93, men who were able to rise from a chair without using hands had an $11 \%$ chance and women a $22 \%$ chance of surviving to 100 ; men and women who were unable to do so had a $2 \%$ chance. Being able to rise from a chair without using hands and having an MMSE score of 28 or greater, one in five men and one in three women would reach the age of 100 . This was three times as high a likelihood as the general likelihood for men and women. 

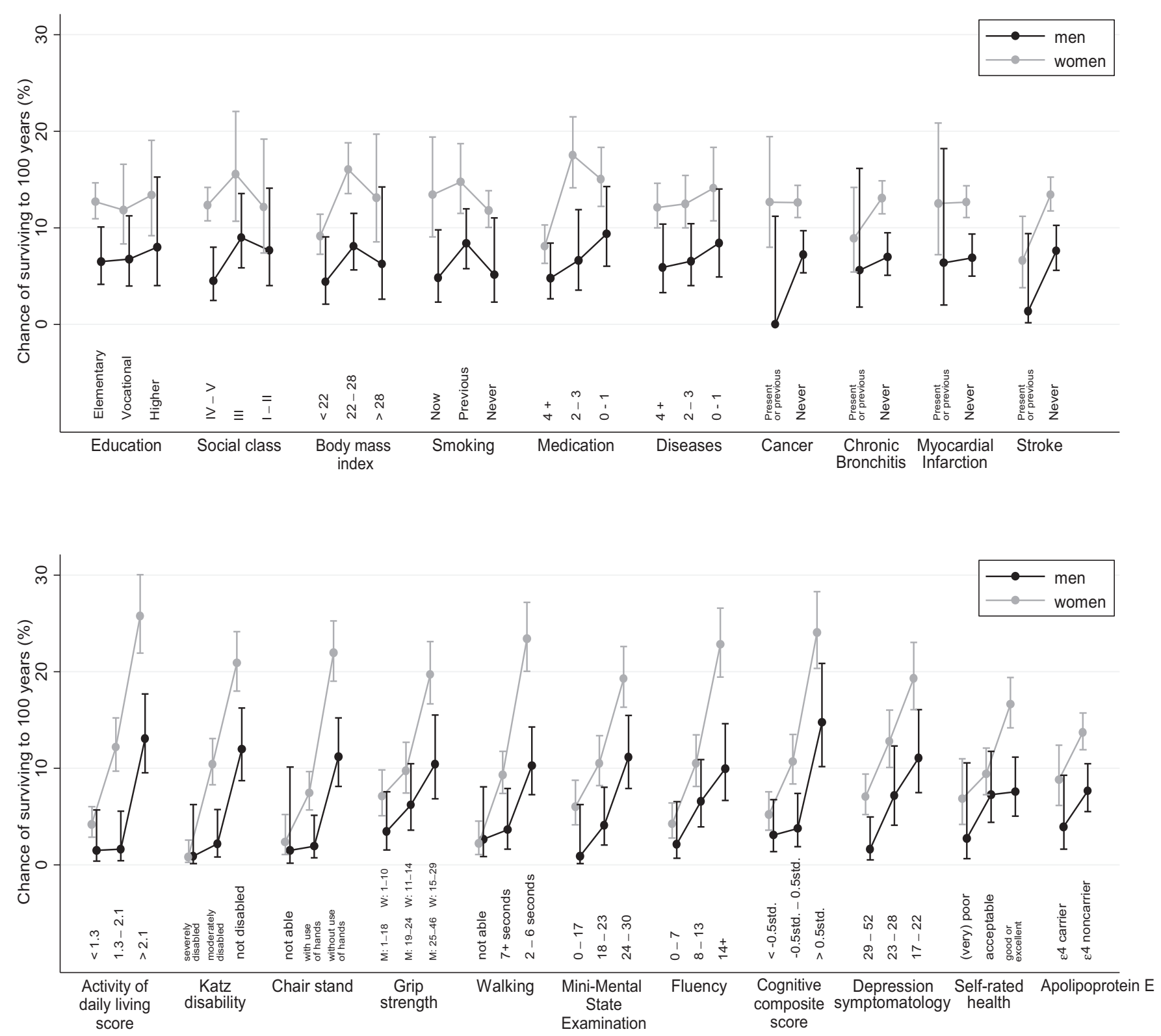

Figure 2. Chance of surviving to 100 estimated using multiple imputation. The categories are the same for all measures for both sexes except for grip strength, as indicated in the figure. Bars indicate $95 \%$ confidence intervals.

Questions about Katz disability would be an alternative to the chair stand because it had an effect size similar to that of the chair stand. A multivariable model also showed that the measures investigated in this study were suitable for differentiating individuals aged 92 to 93 who lived to become 100 from those who did not. Socioeconomic condition, smoking, cancer, chronic bronchitis, and myocardial infarction were not associated with mortality in these very old adults. It is likely that this lack of association was due to selection (e.g., individuals with low socioeconomic status or smokers who survive to very old age are robust). ${ }^{23} \mathrm{~A}$ previous study showed that smokers aged 80 and older had inflammation and lung function levels similar to those who had never smoked and no difference in mortality. ${ }^{24}$

These results are in line with those of other studies, ${ }^{12-15}$ but the results of these studies were presented in a manner that made it difficult to interpret the chance of individual survival. The current study examined easily interpreted measures such as chance of surviving to 100 and average remaining lifespan for individuals aged 92 to 93 , which is possible because of the availability of a large sample from one birth cohort.

A strength of this study is that information on date of death and emigration for all members of the Danish 1905 cohort was obtained through the Danish Civil Registration system and that all persons were invited to participate in the health survey in 1998, regardless of residence, health, or cognitive status. Another strength of the study is that proxy participants were encouraged to participate in the interview if the nonagenarian was unable to participate because of mental or physical disabilities, making lack of information on the most disabled individuals less problematic. Moreover, the use of multiple imputation with 
Table 2. Multivariable Logistic Regression Using Multiple Imputation Analysis Assessing Chance of Surviving to 100 According to Sex

\begin{tabular}{|c|c|c|c|c|}
\hline \multirow[b]{2}{*}{ Factor } & \multicolumn{2}{|c|}{ Men } & \multicolumn{2}{|c|}{ Women } \\
\hline & OR $(95 \% \mathrm{Cl})$ & $P$-Value ${ }^{a}$ & OR $(95 \% \mathrm{Cl})$ & $P$-Value ${ }^{a}$ \\
\hline Education (1-category increase) & $0.60(0.33-1.09)$ & & $0.90(0.66-1.23)$ & \\
\hline Social class (1-category increase) & $1.43(0.82-2.50)$ & & $0.94(0.66-1.35)$ & \\
\hline Body mass index $>22.0 \mathrm{~kg} / \mathrm{m}^{2}$ & $1.66(0.66-4.19)$ & & $1.81(1.29-2.54)$ & \\
\hline Medication (1-unit increase) & $0.94(0.77-1.14)$ & & $0.95(0.88-1.02)$ & \\
\hline Number of diseases (1-unit increase) & $0.92(0.73-1.16)$ & & 1.02 (0.94-1.11) & \\
\hline Never had cancer & - & & $0.87(0.48-1.57)$ & \\
\hline Never had chronic bronchitis & $1.29(0.33-5.05)$ & & $1.56(0.85-2.87)$ & \\
\hline Never had myocardial infarction & $1.60(0.34-7.57)$ & & $1.16(0.58-2.34)$ & \\
\hline Never had stroke & $2.87(0.34-23.97)$ & & $1.34(0.70-2.58)$ & \\
\hline Chair stand (1-category increase) & $1.76(0.62-5.03)$ & & $1.45(0.98-2.13)$ & \\
\hline Grip strength (1-unit increase) & $1.01(0.95-1.08)$ & & $1.03(0.99-1.08)$ & \\
\hline Walking (1-category increase) & $0.45(0.20-1.02)$ & & $1.50(1.03-2.17)$ & \\
\hline Cognition & & .02 & & .003 \\
\hline Mini-Mental State Examination (1-unit increase) & $1.12(0.99-1.27)$ & & $1.02(0.98-1.06)$ & \\
\hline Cognitive Composite Score (1-unit increase) & $1.08(0.95-1.22)$ & & $1.08(1.01-1.14)$ & \\
\hline Depression symptomatology and self-rated health & & .18 & & .71 \\
\hline Depression symptomatology (1-unit increase) & $0.99(0.91-1.08)$ & & $0.99(0.95-1.02)$ & \\
\hline Self-rated health (1-category increase) & $0.52(0.26-1.05)$ & & $0.90(0.67-1.21)$ & \\
\hline Apolipoprotein E \&4 noncarrier & $2.35(0.83-6.63)$ & .11 & $1.82(1.17-2.83)$ & .008 \\
\hline
\end{tabular}

${ }^{\text {a }} P$-value is from a joint test of the variables in the category being able to predict the chance of surviving to 100 .

$\mathrm{OR}=$ odds ratio $\mathrm{CI}=$ confidence interval; $\mathrm{ADL}=$ activity of daily living.

Table 3. Combined Results of Chair Stand and Mini-Mental State Examination or Chair Stand and Activity of Daily Living Disability According to Sex

\begin{tabular}{|c|c|c|c|c|c|c|c|}
\hline \multirow{2}{*}{ Test } & & \multicolumn{3}{|c|}{ Men } & \multicolumn{3}{|c|}{ Women } \\
\hline & & $\begin{array}{c}\text { Prevalence } \\
\text { at Age } \\
92-93, \%\end{array}$ & $\begin{array}{c}\text { Likelihood } \\
\text { of Reaching } \\
100, \%\end{array}$ & $\begin{array}{c}\text { Average } \\
\text { Remaining } \\
\text { Lifespan, } \\
\text { Years (Relative }{ }^{a} \text { ) }\end{array}$ & $\begin{array}{c}\text { Prevalence } \\
\text { at Age } \\
92-93, \%\end{array}$ & $\begin{array}{c}\text { Likelihood } \\
\text { of Reaching } \\
100, \%\end{array}$ & $\begin{array}{c}\text { Average } \\
\text { Remaining } \\
\text { Lifespan, } \\
\text { Years (Relative }{ }^{\mathrm{a}} \text { ) }\end{array}$ \\
\hline Chair stand & \multicolumn{7}{|c|}{ MMSE score } \\
\hline Can with use of hands & $18-23$ & 14 & 1.3 & $2.1(0.8)$ & 17 & 7.8 & $3.1(0.9)$ \\
\hline Can with use of hands & $24-30$ & 13 & 4.0 & $3.0(1.1)$ & 14 & 9.0 & $3.6(1.1)$ \\
\hline Can without use of hands & $0-17$ & 6 & 3.0 & $2.0(0.7)$ & 6 & 13.3 & $3.4(1.0)$ \\
\hline Can without use of hands & $18-23$ & 15 & 8.1 & $3.3(1.2)$ & 14 & 17.2 & $4.2(1.3)$ \\
\hline Can without use of hands & $24-27$ & 22 & 10.2 & $3.5(1.3)$ & 16 & 24.6 & $4.9(1.5)$ \\
\hline Can without use of hands & $28-30$ & 11 & 21.7 & $4.3(1.6)$ & 6 & 34.2 & $5.6(1.7)$ \\
\hline Moderately disabled & $24-30$ & 13 & 2.7 & $2.7(1.0)$ & 14 & 13.6 & $3.9(1.2)$ \\
\hline Not disabled & $0-17$ & 4 & 4.0 & $2.4(0.9)$ & 5 & 12.2 & $3.4(1.0)$ \\
\hline Not disabled & $18-23$ & 13 & 7.7 & $3.3(1.2)$ & 13 & 18.5 & $4.4(1.3)$ \\
\hline Not disabled & $24-27$ & 21 & 11.7 & $3.6(1.3)$ & 16 & 21.4 & $4.6(1.4)$ \\
\hline Not disabled & $28-30$ & 12 & 20.1 & 4.5 (1.7) & 6 & 32.2 & $5.6(1.7)$ \\
\hline
\end{tabular}

Analyses were performed using multiple imputation.

${ }^{\text {a}}$ Relative to overall average remaining lifespan: 2.7 for men, 3.3 for women.

MMSE $=$ Mini-Mental State Examination. 
information from proxies and nonproxies makes inference about the association between the measures, which were measured only in nonproxies, and mortality less biased. Handling of missing data using multiple imputation is important in clinical trials and observational studies. ${ }^{25}$

A weakness of the study is that it includes only one birth cohort from one country. Hence, an important question is whether the results can be generalized to other countries and younger birth cohorts, but the measures are well validated and used across high-income countries where life expectancy for nonagenarians is fairly homogenous (Online Table S1), and the use of relative estimates is likely to ensure generalizability for other countries and newer cohorts. Another potential problem is that, even though the participation rate from the health survey was high $(63 \%)$, nonresponse from the frailest individuals could create biased associations. Using data from the Danish Civil Registration system, the participants were compared with the nonparticipants, and it was found that the nonparticipants had a shorter average remaining lifespan that the survey participants, indicating that the prevalence of poor health was higher than stated in this manuscript and that the average remaining lifespan of people performing poorly is probably overestimated. The average remaining lifespan of those performing well would most likely not be biased.

Ageism in treatment of very old adults who are well functioning has decreased over the last decade, and medical procedures for this age group have been examined, ${ }^{4,5}$ but overtreatment of very old adults is of concern, and potential side effects and complications associated with treatment must be balanced with the overall survival prognosis. ${ }^{8}$ The life expectancy for an 80 -year-old ranges from 8 to 10 years in high-income countries but is still fairly short for 90 -year-olds, ranging from 4 to 5 years. Comprehensive geriatric assessment instruments aim to identify current health problems and assist in medical decisionmaking, ${ }^{6,9}$ but they are generally time-consuming. Simpler screening tools exist, but the have mostly been validated in people aged 70 to $80 . .^{10,11}$

For nonagenarians, being able to rise from a chair without using hands and having an MMSE score of 28 or greater, the average remaining lifespan was 1.6 to 1.7 times as high as that for men and women in general. Translating this to the life expectancy seen in Denmark in 2009 to 2012 would indicate a life expectancy today of 6.3 years for men and 7.7 years for women at age 92 to 93. Chair stand score combined with MMSE score is a quick and easy way to estimate overall chance of survival in very old adults, which is important to take into consideration when making major clinical decisions.

\section{ACKNOWLEDGMENTS}

The authors wish to thank Karen Andersen-Ranberg, MD, for helpful input and discussion during the conduction of this study.

The Danish 1905 cohort survey was supported by grants from the Danish National Research Foundation and U.S. National Institutes of Health, National Institute on Aging Grant NIA-P01-AG08761. The Danish Aging Research Center is supported by a grant from the VELUX foundation.
Conflict of Interest: We declare that we have no conflicts of interest.

Author Contributions: Thinggaard: data analysis, drafting the manuscript. Christensen, Jeune, Vaupel: study initiation, obtaining funding, drafting the manuscript. McGue: protocol design, data analysis, drafting the manuscript. Osler: obtaining funding, data analysis, drafting the manuscript. All authors read and approved the final version.

Sponsor's Role: The sponsors of the study had no role in study design, data collection, data analysis, data interpretation, or writing of the report.

\section{REFERENCES}

1. Christensen K, Doblhammer G, Rau R et al. Ageing populations: The challenges ahead. Lancet 2009;374:1196-1208.

2. Christensen K, Thinggaard M, Oksuzyan A et al. Physical and cognitive functioning of people older than 90 years: A comparison of two Danish cohorts born 10 years apart. Lancet 2013;382:1507-1513.

3. Boon NA. New deal for old hearts. BMJ 1991;303:70.

4. Alfonso DT, Howell RD, Strauss EJ et al. Total hip and knee arthroplasty in nonagenarians. J Arthroplasty 2007;22:807-811.

5. George I, Yerebakan H, Kalesan B et al. Age alone should not preclude surgery: Contemporary outcomes after aortic valve replacement in nonagenarians. J Thorac Cardiovasc Surg 2014;148:1360-1369.e1.

6. Rivoirard R, Chargari C, Trone JC et al. General management of nonagenarian patients: A review of the literature. Swiss Med Wkly 2014;144:w14059.

7. Human Mortality Database [on-line]. Available at http://www.mortality.org/ Accessed July 11, 2014.

8. Smith AK, Williams BA, Lo B. Discussing overall prognosis with the very elderly. N Engl J Med 2011;365:2149-2151.

9. Extermann M, Aapro M, Bernabei R et al. Use of comprehensive geriatric assessment in older cancer patients: Recommendations from the task force on CGA of the International Society of Geriatric Oncology (SIOG). Crit Rev Oncol Hematol 2005;55:241-252.

10. Decoster L, Van Puyvelde K, Mohile S et al. Screening tools for multidimensional health problems warranting a geriatric assessment in older cancer patients: An update on SIOG recommendations. Ann Oncol 2015;26:288-300.

11. Yourman LC, Lee SJ, Schonberg MA et al. Prognostic indices for older adults: A systematic review. JAMA 2012;307:182-192.

12. Formiga F, Ferrer A, Chivite D et al. Predictors of long-term survival in nonagenarians: The NonaSantfeliu study. Age Ageing 2011;40:111-116.

13. Tiainen K, Luukkaala T, Hervonen A et al. Predictors of mortality in men and women aged 90 and older: A nine-year follow-up study in the Vitality 90+ study. Age Ageing 2013;42:468-475.

14. Lee SJ, Go AS, Lindquist $\mathrm{K}$ et al. Chronic conditions and mortality among the oldest old. Am J Public Health 2008;98:1209-1214.

15. Cesari M, Onder G, Zamboni V et al. Physical function and self-rated health status as predictors of mortality: Results from longitudinal analysis in the ilSIRENTE study. BMC Geriatr 2008;8:34.

16. Guralnik JM, Ferrucci L, Simonsick EM et al. Lower-extremity function in persons over the age of 70 years as a predictor of subsequent disability. N Engl J Med 1995;332:556-561.

17. Guralnik JM, Simonsick EM, Ferrucci L et al. A short physical performance battery assessing lower extremity function: Association with selfreported disability and prediction of mortality and nursing home admission. J Gerontol 1994;49:M85-M94.

18. Nybo H, Gaist D, Jeune B et al. The Danish 1905 cohort: A genetic-epidemiological nationwide survey. J Aging Health 2001;13:32-46.

19. Nybo H, Gaist D, Jeune B et al. Functional status and self-rated health in 2,262 nonagenarians: The Danish 1905 Cohort Survey. J Am Geriatr Soc 2001;49:601-609.

20. Nybo H, Petersen HC, Gaist D et al. Predictors of mortality in 2,249 nonagenarians-the Danish 1905-Cohort Survey. J Am Geriatr Soc 2003;51:1365-1373.

21. Pedersen CB, Gotzsche H, Moller JO et al. A cohort of eight million persons. Dan Med Bull 2006;53:441-449.

22. Rubin DB. Multiple imputation after $18+$ years. J Am Statistical Assoc 1996;91:473-489.

23. Vaupel JW, Yashin AI. Heterogeneity's ruses: Some surprising effects of selection on population dynamics. Am Stat 1985;39:176-185. 
24. Levine M, Crimmins E. Not all smokers die young: A model for hidden heterogeneity within the human population. PLoS One 2014;9:e87403.

25. Little RJ, D'Agostino R, Cohen ML et al. The prevention and treatment of missing data in clinical trials. N Engl J Med 2012;367:1355-1360.

\section{SUPPORTING INFORMATION}

Additional Supporting Information may be found in the online version of this article:

Appendix S1. Extended description of the selected measures in this study and a more in-depth description of the multiple imputation used in the statistical analysis.

Table S1. Life expectancy (period mortality).

Table S2. Chance of surviving to 100 years for selected measures at 92-93 years of age using complete case analysis.

Please note: Wiley-Blackwell is not responsible for the content, accuracy, errors, or functionality of any supporting materials supplied by the authors. Any queries (other than missing material) should be directed to the corresponding author for the article. 